\title{
La dinámica placer/afecto en la constitución de feminidades en mujeres negras y mestizas-blancas de diferentes sectores sociales en el suroccidente colombiano
}

\author{
Fernando Urrea Giraldo \\ Magister en Ciencia Política \\ Profesor Titular Dpto. de Ciencias Sociales \\ Facultad de Ciencias Sociales y Económicas \\ Universidad del Valle \\ Cali, Colombia
}

>furreagiraldo@yahoo.com

Jorge Eduardo Moncayo Quevedo

Magister en Sociología

Docente Universidad Antonio Nariño

Cali, Colombia

> eduardo20019@hotmail.com 
Resumen: Este articulo analiza la producción de determinadas feminidades en el suroeste colombiano actual, a través de las tensiones entre placer y afecto reveladas por las biografías sexuales de 18 mujeres negras y blancas-mestizas, de diferentes clases sociales, color de piel, orientación sexual, generación, edad, estado civil y prole. A través de la construcción de cuatro tipologías, se aborda el papel creciente del placer en la conformación social de las subjetividades contemporáneas. Parte de los resultados son debatidos a partir de la perspectiva foucaultiana, el feminismo radical, la teoría queer, y el psicoanálisis lacaniano, con aportes de la sociología y el feminismo afroamericano. El presente texto se inscribe en la teoría feminista de la interseccionalidad, y plantea especialmente el papel de la racialización en la vivencia de la sexualidad de las mujeres negras entrevistadas, mediante la articulación de las dimensiones sexual y racial.

Palabras claves: feminidad; subjetividad; placer; afecto; racialización

\section{A dinâmica prazer/afeto na constituição de feminilidades em mulheres negras e mestiças-brancas de diferentes setores sociais no sul ocidental colombiano}

Resumo: Neste artigo analisa-se a produção de determinadas feminilidades no sul ocidental colombiano atraves das tensões entre prazer e afeto que revelam as biografias sexuais de 18 mulheres negras e brancas-mestiças de diferentes classes sociais, cor de pele, orientação sexual, geração, idade, estado civil e prole. Através de quatro tipologias construídas, aborda-se o papel crescente do prazer na conformação social das subjetividades em um contexto contemporâneo. Isto permite debater parte dos resultados a partir da perspectiva foucaultiana, o feminismo radical, a teoria queer e a psicanálise lacaniana, com contribuições da sociologia e do feminismo afro-americano. Por outro lado, este texto se inscreve na teoria feminista da interseccionalidade, colocando sobretudo o papel da racialização na vivência da sexualidade das mulheres negras entrevistadas, mediante a articulação das dimensões sexual e racial.

Palavras-chave: feminilidade; subjetividade; prazer; afeto; racialização

\section{Pleasure/affection dynamics and femininities among black and white- mestizo women of different social sectors in the Colombian southwest}

Abstract: This article analyzes the production of certain femininities by looking at the tensions between pleasure and affection arising from the sexual biographies of 18 black and white-mestizo women, of different social classes, skin color, sexual orientation, generation, age, marital status, and offspring contemporary south-western Colombia. Four typologies constructed by this investigation reveal the rising role of pleasure in the conformation of contemporary subjectivities. Results are discussed in a Foucaultian perspective, with the tools of radical feminism, queer theory and Lacanian psychoanalysis. This sociological analysis also benefits from Afro-American feminism. Using feminist intersectionality theory, it pays particular attention to the role of racialization, by articulating the sexual and racial experience of black interviewees.

Keywords: Femininity; subjectivity; pleasure; affection; racialization 
Tu me dices que si él te hacía una, tu le hacias el doble. ¿En ese momento llegaste a tener relaciones simultáneas con él y otros chicos?

- Sí, claro que sí. Bueno (...) fueron tiempos muy largos, Si uf... tuve varios y yo me enamoré igual, yo no sé, pero yo definitivamente pude (....) al mismo tiempo. Inclusive había momentos de que en el mismo día tenía una relación (con otro hombre) y luego tenía la relación con él.

¿Y no tenias ningún tipo de cuestionamiento para ti ni te causaba culpa?

- No, para nada (...) Los dos me hacían falta, claro que generalmente alguno de los dos tenía que saberlo, el amante sabía que yo tenía un novio de toda la vida y entonces mi novio no se daba cuenta que yo andaba con el otro y se hacía como más interesante la cosa cuando yo me le volaba a éste para irme con el otro.

(Leticia, mujer mestiza-blanca, 53 años, heterosexual, soltera, con dos hijos, estudios universitarios completos, asalariada de nivel ejecutivo, residente en un barrio de clase media alta de Cali).

\section{Introducción}

Este artículo explora mudanzas contemporáneas en las percepciones sobre el cuerpo femenino como experiencia de placer, a través de fragmentos de 18 biografías sexuales de un conjunto de mujeres negras y mestizas-blancas, de diferentes clases sociales, generaciones y orientación sexual, en el suroccidente colombiano. En el texto se analizan dichos procesos en experiencias heterosexuales y no heterosexuales, y los límites que marcan esos cambios, especialmente entre mujeres negras homosexuales. De esta manera, el estudio aborda las relaciones entre placer y afecto, amor romántico y proyecto de feminidad, así como las consecuencias en términos de las relaciones de poder entre mujeres y hombres, y las posibles fisuras en las formas de dominación patriarcal que podrían estar desarrollándose en determinadas sociedades de América Latina, como la colombiana.

Los 18 sujetos femeninos seleccionados - de quienes se ofrecen fragmentos sobre sus experiencias sexuales- integran un estudio más amplio que se soporta empíricamente en 82 entrevistas en profundidad alrededor de biografías sexuales 
y en otras técnicas de investigación. ${ }^{1}$ En términos metodológicos, el artículo combina un diálogo entre el análisis socio-antropológico y el psicoanálisis, utilizando como recurso empírico las entrevistas. ${ }^{2}$ La problemática que traza el texto gira en torno a los aportes construccionistas del feminismo en sus vertientes más críticas, en conexión con la perspectiva queer, en permanente debate con el psicoanálisis, especialmente de influencia lacaniana. Esto último se podrá observar a través del uso de determinadas categorías. Sin embargo, como se trata de un estudio empírico desde las ciencias sociales, nos interesa la producción de las subjetividades femeninas en articulación con determinaciones que, a la vez, generan desigualdades sociales, para lo cual apostamos por un enfoque de interseccionalidad en la dirección del feminismo afroamericano. Por ello, el principal problema que orienta el artículo es la producción de determinadas feminidades -como subjetividades específicas- en el suroccidente colombiano, mirada a partir de la tensión entre placer y afecto, en un contexto de modernidad atravesado por factores de clase social y étnico-raciales.

Se asume una compleja y rica interacción entre raza, etnicidad y clase social, para la región y para la sociedad colombiana, en la producción de feminidades y masculinidades, y en las diversas manifestaciones de las sexualidades que tienen que ver con las identidades femeninas. En todo momento pensamos que están atravesadas por la connotación racial y de clase social, a través de la articulación sexo/ raza (Wade, 2009). Por precaución conceptual y metodológica se han excluido del

1 Nos referimos al proyecto "Feminidades y sexualidades: mujeres negras, indígenas, mestizas-blancas y transgeneristas negras en el suroccidente colombiano", realizado entre los años 2008 y 2009 por el grupo de investigación de la Universidad del Valle (Cali, Colombia) "Estudios étnico-raciales y del trabajo en sus diversos componentes", bajo la coordinación de Fernando Urrea Giraldo. El equipo estuvo constituido por las antropólogas Jeanny Posso Quiceno y Nancy Motta González, y como asistentes de investigación y estudiantes monitores, José Ignacio Reyes Serna, Claudia Lorena Mera, Astrid Yulieth Cuero Montenegro, Consuelo Malatesta Morera, Waldor Arias Botero, Yenny Velasco, Jairo Alexander Castaño López, Flor Delia Vitonás y Oswaldo Viera Martínez. El estudio trabajó biografías sexuales de 69 mujeres, 9 hombres y 4 transgeneristas negras; 45 mujeres negras y mestizas/ blancas; 4 hombres negros y mestizos/blancos; 24 mujeres indígenas y 5 hombres indígenas. Entre las mujeres negras y mestizas/blancas de clases medias altas, medias medias y clases populares se incluyeron 8 mujeres cuya sexualidad era no normativa (vivencias homosexuales y bisexuales). Para este artículo se han seleccionado únicamente entrevistas de mujeres negras y mestizas-blancas de las ciudades de Cali y Buenaventura, y del poblado de Villa Rica, ubicado en el norte del departamento del Cauca, área metropolitana ampliada de Cali. Se agradece igualmente al grupo de investigación en psicología (GRIPSI) de la Universidad Antonio Nariño, a través de la participación del investigador Jorge Eduardo Moncayo Quevedo, coautor del artículo.

2 Los fragmentos de las entrevistas de biografías sexuales son empleados aquí como material sujeto a interpretación bajo una doble lectura: socio-antropológica y psicoanalítica. 
análisis las entrevistas a mujeres indígenas, debido al riesgo de hacer una lectura simplista sobre las condiciones de producción del género y las sexualidades en las sociedades indígenas a partir de mujeres urbanas. Igualmente, se han dejado de lado las transgeneristas negras, por entender que ameritan un tratamiento específico.

\section{Un acercamiento a la(s) sexualidad(es) y feminidad(es) contemporáneas}

Partimos considerando la dimensión de la sexualidad como una esfera específica de las relaciones sociales. Esto remite a autores que establecen conceptualmente un campo y un capital sexual (Martin \& George, 2006), a partir del modelo analítico de Bourdieu, pero bajo un régimen diferente a los diversos tipos de campos y capitales que se caracterizarían por mecanismos de mercado (Bourdieu,1979). Para Martin \& George (2006), la sexualidad conformaría un espacio social en el sentido de Bourdieu, pero sin regirse por la metáfora del mercado. Si bien la dimensión sexual es un componente en toda sociedad, la principal característica a lo largo del siglo XX -y en especial desde los años 1960- ha sido su conformación como un campo autónomo, a diferencia de procesos sociales anteriores en los cuales esa dimensión estaba subordinada a los campos económico, político, cultural, religioso, entre otros (Giddens,1991; 1992).

La sexualidad en este texto es mirada como organización social del deseo y el placer (Green, 2008), y siguiendo la dirección de Foucault:

Desde hace casi ciento cincuenta años, está montado un dispositivo complejo para producir sobre el sexo discursos verdaderos: un dispositivo que atraviesa ampliamente la historia puesto que conecta la vieja orden de confesar con los métodos de la escucha clínica. Y fue a través de ese dispositivo como, a modo de verdad el sexo y sus placeres, pudo aparecer algo como la sexualidad (1977:86).

Algunas de las transformaciones en la sexualidad contemporánea son descritas por Bajos y Bozon, quienes a partir de la sociedad francesa señalan:

(...) el pasaje progresivo de un modelo estatutario, en donde el derecho a tener sexo cambia del estatuto matrimonial al de un modelo interpersonal, mediante el cual el intercambio sexual funciona como base y motor de las relaciones, generando nuevas expectativas sociales a través de la sexualidad, en particular el reconocimiento del derecho de los individuos, sobre todo de las mujeres, a tener una vida sexual placentera (2008:582. La traducción nos pertenece). 
Los hallazgos de Bajos \& Bozon (2008:589) referidos a las conquistas en la vivencia de la sexualidad de las mujeres francesas respecto de los hombres, se habrían manifestado en una diversificación de sus experiencias sexuales. Esto confirmaría formulaciones de Giddens en su obra clásica sobre las transformaciones de la intimidad, donde coloca a las mujeres como principales agentes del cambio. Esa creciente autonomización de la sexualidad se articularía con procesos de individuación/subjetivación en las sociedades contemporáneas (Giddens,1992).

Transformaciones de la sexualidad y su impacto en la producción del Ego afectan en las sociedades contemporáneas tanto a mujeres como a hombres, al igual que a las figuras de pasaje, que juegan con las representaciones masculinas/femeninas y las ambigüedades sexo/género (transgeneristas), en cuanto individuos en dinámicas de subjetivación performativa (Butler,1993; 2004). Las categorías de identidad sexual y de género, y lo que se constituye como feminidades en plural, son asumidas en este texto a partir del debate que introduce Foucault y el feminismo en su vertiente radical -Rubin (1996), Mathieu (2005), Wittig (2010), entre otras- que retoma aportes foucaultianos y una perspectiva queer (Butler,1993).

En esa dirección, designamos provisoriamente como feminidades o identidades femeninas a formas empíricas de construirse como mujer en términos de los papeles sociales sexo/género que operan en una sociedad concreta, y que tienden a ser asignados culturalmente a figuras femeninas, muchas veces en forma independiente del sexo biológico, en la perspectiva de Goffman $(1976$; 1977) y West \& Zimmerman (1999). Nos apartamos de una mirada esencialista sobre las categorías de mujer y hombre, ya que en términos de la relación fluida o ambivalente entre identidad de sexo/género y sexo biológico los fenómenos de individuación conllevan a que cada individuo fabrique su propia identidad. ${ }^{3}$

En este trabajo nos interesan las feminidades, aunque no de manera genérica sino atravesadas por determinaciones de tipo étnico-racial, de clase social y de cohorte generacional; y también bajo las nuevas regulaciones o controles sociales de la sexualidad (Martin Alcoff, 2006). Al introducir el componente étnico-racial, nos ubicamos en el terreno de la población negra/mulata, afro-

3 Para Butler (1993), el sujeto opera como una estructura discursiva (lingüística) en permanente constitución o formación. Por ello, la función del sujeto en el discurso (su posición) es la subjetividad en sí misma (subjecthood). La identidad subjetiva no está dada, ya que el sujeto está en una dinámica de producción sin fin, lo cual significa que hay muchas posibilidades de identidades. Las categorías de "sujeto femenino" (o "masculino") y mujer (u hombre) ya no son estables y definidas. Un enfoque queer que se alimenta de esta línea reflexiva trabaja con categorías móviles, transitivas, es, por excelencia, construccionista. 
colombiana o afrodescendiente, en términos comparativos con la población blanca y mestiza de mujeres y hombres.

\section{Ejes analíticos para la indagación de las subjetividades femeninas}

Aunque las categorías de placer y afecto tienen un soporte consolidado en el psicoanálisis, el abordaje analítico que usaremos retoma una lectura más próxima de Foucault y Butler. Consideramos el placer (sexual) en el sentido de experiencia vivida como un goce corporal indeterminado y radical (también como "intensificación del placer" $)^{4}$ en el aquí y el ahora, sin reducirlo al campo genital, ya que afecta a toda la dimensión corporal, porque cualquier parte del cuerpo entra potencialmente en la esfera del goce radical. Cada sujeto produce su objeto de goce, sin que exista de forma teleológica pre-establecida, organizado bajo una supuesta estructura simbólica a-social. ${ }^{5}$ Además, el placer es la experiencia corporal a partir de una fantasía sexual, la cual siempre es socialmente construida o producida a partir de actos discursivos. Por lo mismo, no es un fenómeno instintivo ni pulsional, sino un mecanismo de significantes que la sociedad produce a lo largo de los procesos históricos como representaciones/imágenes de sujetos/objetos de deseo, actos performativos que toman forma en las fantasías sexuales. ${ }^{6}$ En tercer lugar, el placer como aquí lo consideramos es una materialización del deseo; en oposición a la sublimación freudiana y a la primacía en la sexualidad que tiene el deseo sobre

4 Según Allouch (2001:200-201) la perspectiva de Foucault sería equivalente a lo que, en Lacan, se denomina plus-de-goce; pero en la dirección que aquí se le da al placer, vinculado al cuerpo, igualmente tendría que ver con el goce fálico lacaniano (Lacan, 1973:70). Como a continuación veremos, nos acercamos más a la interpretación performativa de Butler del falo lesbiano.

5 En Butler (1993:57, 59, 79), la idea del falo lesbiano opera como otro juego performativo que desafía el orden simbólico e imaginario hegemónico del falo-pene.

6 Esto último se apoya en Butler por cuanto no existiría una estructura simbólica corporal anterior a lo social, ya que tanto el pene como el falo son socialmente construidos por el discurso; en otras palabras, son elementos performativos (1993:57); véase también Green (2008). 
el placer para Lacan, que no comparte Foucault. ${ }^{7}$

En el presente trabajo el afecto opera como la otra dimensión de la subjetividad que está en continua tensión con el placer, y que permite además entender en interacción con éste diferentes modulaciones de las feminidades actuales. Desde el psicoanálisis lacaniano el mundo afectivo no se constituye simplemente de emociones "primarias", como opuesto a la esfera intelectual. El afecto incluye ambos componentes a través del orden simbólico. Aunque Lacan no proponga una teoría general del afecto y particularmente lo aborde a través de la cura psicoanalítica (Evans, 1997:32), de todas maneras significa que el sujeto es afectado en la relación con el Otro (Lacan, 1988:102-103). En la medida en que el afecto sólo se determina por el significante, se produce una indeterminación en lo que se considera vivido como afecto, por lo que se trata de una idealización/emoción imprecisa, escurridiza, nada fácil de asir. ${ }^{8}$ De todos modos, el afecto opera como una idealización que hace el Ego del Otro, por vía del orden discursivo, lo que permite moldear el deseo en cada formación social histórica, como una condición para que se produzca el

7 Según Foucault $(1979 ; 1983)$, la distinción entre deseo y placer es fundamental para el psicoanálisis, en su análisis de la fabricación de la sexualidad y el sexo en la modernidad. Dicha distinción es central, de acuerdo con el interesante análisis de García (2009:55): “[En la modernidad] el acento y la atención es puesta en el deseo, sólo el deseo importa y el acto ha de ser puesto al servicio del deseo y no del placer; deseo que jamás ha de cumplirse, ya que su cumplimiento se erige en su misma pérdida y evaporación (...)”. Al focalizar el psicoanálisis principalmente al deseo como lo determinante de la sexualidad, éste se convierte en un fin vacío, sin salida para todo sujeto; así, el placer queda condenado a un juego narcisista que se materializa en las perversiones. Véase también la excelente exposición que hace sobre este punto Roudinesco (2009) a partir de su posición lacaniana. Bajo cierta perspectiva lacaniana, afirmar el placer por el sujeto, característico del narcisismo en las sociedades contemporáneas, deriva en la peligrosa disolución de la frontera entre lo normal y lo patológico, la cual se sustenta en el orden de sexo/género binarista. En una dirección próxima, se ubicaría la crítica que las antropólogas feministas Gestin \& Mathieu (2010:64-76) hacen a Lévi-Strauss, al advertir que este autor naturaliza y esencializa un modelo de parentesco sexo/género binarista que inevitablemente se soporta en la diferencia biológica sexual. O sea, la prevalencia del parentesco heterosexual se constituye en ley universal. Esta crítica ya estaba contenida en Rubin (1986:95-145), como lo advierten las autoras (Gestin \& Mathieu, 2010:64-76).

8 Advertimos que, en el enfoque lacaniano, el afecto también tiene que ver con otros aspectos del orden subjetivo, como la angustia. "Cuando se trata del amor o el odio, por ejemplo, estaríamos más bien frente a afectos del yo, que circulan como eslabones de la cadena significante. La angustia no se ubicaría en dicha cadena, sino que ancla en lo que se dará en llamar el objeto a." (Chairo, 2010:36). 
lazo social en la misma. ${ }^{9}$ Por ello, el afecto en cada sociedad se aproxima a una manera de amar, incidiendo en las subjetividades que, para el caso en estudio, son identidades femeninas en la sociedad colombiana de hoy.

Quizás haya sido Simmel (1934), desde las ciencias sociales, quien introdujera con más fuerza el tema de la afectividad en los procesos de subjetivación como parte de las condiciones de la modernidad, especialmente en lo referido a la cultura femenina. Para el autor, el hombre ama a la mujer en general y se vincula a todas las mujeres, mientras que las mujeres se vinculan a un hombre en particular (Simmel, 1934:17-21). Este acercamiento sociológico a procesos de subjetivación de las identidades femeninas, como parte de fenómenos culturales históricos que anteponen al placer el afecto y la entrega al esposo o compañero, aunque signifique la renuncia a tener una experiencia erótica, es clave para entender lo que en Simmel es la fidelidad femenina versus la infidelidad masculina (1934:21-22), constituyendo un elemento importante en la ideología del amor romántico.

En una dirección cercana, Kaufmann (2003) en su libro de sociología de la pareja advierte que "los hombres privilegian el apoyo afectivo inmediato y egoísta ya que ellos están menos implicados en la pareja, al contrario de las mujeres quienes lo inscriben por la razón opuesta en la comunicación conyugal” (2003:105). Este autor señala previamente que el afecto, como "sentimiento amoroso (...) está igualmente ligado a la construcción de la identidad personal” (2003:44). Más adelante, puntualiza que el sentimiento amoroso se inscribe así en la normalidad del proceso identitario. Pero, como anota Simmel (apud Kaufmann, 2003:45), "la pasión más absoluta es también la más frágil por cuanto ella se sitúa en una lógica de fuga de la realidad” . Esta pista analítica desde la sociología será fundamental cuando analicemos los relatos sobre las experiencias eróticas y amorosas de las mujeres participantes del estudio presentado.

9 “Para Lacan, el afecto está ligado siempre a nuestra relación con el Otro, es decir a aquello que nos constituye como sujetos deseantes (....) Siguiendo a Lacan, podemos sostener que somos, en lo que nos afecta y en tanto sujetos, siempre dependientes de ese deseo que nos liga con el Otro y que nos obliga a no ser más que ese objeto siempre desconocido y faltante (Chairo, 2010:37). Es de resaltar que, en los últimos años, existe un incremento en los trabajos de psicoanálisis frente al tema del afecto. Véase al respecto el reciente libro de Soler, Les affects lacaniens (2011). 


\section{Los planos de la interseccionalidad de las feminidades}

En la producción de las subjetividades femeninas es preciso tomar en cuenta el la clase social ${ }^{10}$ y lo racial, a través del fenómeno del color de piel, ${ }^{11}$ el nivel sociodemográfico (generación y grupo etario, estado conyugal y presencia de prole ${ }^{12}$ ) y la orientación sexual, componente ésta de la trayectoria biográfica individual. Como esquema analítico que ayuda a trabajar el enfoque de interseccionalidad ${ }^{13}$, nos apoyamos en la categoría matriz de dominación propuesta por Collins (1990:221) advirtiendo, junto con la autora, que las dimensiones sociales que la componen tienen combinaciones diferenciadas, según procesos históricos concretos. Bajo dicha orientación analítica, uno de los ejes que articula este proceso identitario en permanente tensión se manifiesta a través de la racialización de la sexualidad y, en sentido inverso, la sexualización de lo racial.

La articulación entre sexualidad y racialidad ha sido propuesta en trabajos de corte sociológico, desde una perspectiva feminista, como el de Nagel (2003); y desde la antropología, en Wade (2009). Esta determinación social permite deconstruir la pareja raza-sexo, puesto que en diferentes sociedades ambos componentes se sustentan en una naturalización biológica. Este efecto ideológico-biologista se cuela en los estereotipos sexuales que enfrentan los diferentes grupos étnico-raciales, en lo que para Nagel constituyen atributos etnosexuales. Simultáneamente se produce un fenómeno en sentido contrario: la racialización de los sujetos encarnados en cuerpos sexuados (Green, 2008), pues las fantasías sexuales tienen, además de olores y sabores, colores de piel. Aunque entren en juego otras categorías en la producción de lo afectivo y del placer -como la clase, la generación, la edad, el estado civil y la presencia de hijos/as- pareciera que la dimensión racial (color de piel) tiene, en los sujetos femeninos estudiados, un efecto

10 Para efectos de la clase social usamos como indicadores proxy el nivel educativo alcanzado y el barrio donde vive la informante, así como su ocupación.

11 Lo racial entendido como un dispositivo pigmentocrático que interactúa con la clase social, de acuerdo con los hallazgos del estudio PERLA (Proyecto de Etnicidad y Raza en América Latina) para cuatro países de la región (Brasil, Colombia, México y Perú), coordinado por Edward Telles (Princeton University). Según Urrea, Viáfara \& Viveros (2012), Colombia es una pigmentocracia social en la que el género articula a la vez el proceso de producción de desigualdades sociales por clase y raza, mediante las parejas blanquitud-feminidad y negritud-masculinidad. De esta manera, las clases sociales tienen colores de piel.

12 Hijos/as: para efectos de este estudio no se diferencia el sexo/género de los hijos ni sus edades, sólo la presencia o no de un determinado número de hijos en cada entrevistada.

13 La categoría de interseccionalidad ha sido principalmente un aporte del feminismo afroamericano, conocido como "black feminism". Para un estado del arte sobre esta categoría, véase Bilge, 2009. 
de sobredeterminación de las esferas afectiva y del placer sexual. Asimismo, la manera como entra en juego la orientación sexual en la identidad femenina es otro factor que incide en la tensión entre placer y afecto, y en las formas de resolución en las biografías sexuales. Esto, como se verá más adelante, se capta en las mujeres negras lesbianas entrevistadas.

\section{Hacia una tipología de subjetividades femeninas en el suroccidente colombiano}

Frente a la diversidad de feminidades con las que se trabajó en la investigación original, para este artículo hemos desarrollado cuatro tipologías sociales empíricas, que buscan dar cuenta de las tendencias de las subjetividades femeninas en una región colombiana específica. Partimos de que la subjetividad femenina como la masculina- es compleja, y nuestra intención es proponer una tipología que contribuya a la comprensión de las subjetividades en el espacio de la modernidad contemporánea en una región de la periferia capitalista. Advertimos de partida, sin embargo, que estas feminidades abordadas se sitúan en un juego ambiguo de continuidad/discontinuidad.

\section{Feminidades subordinadas alrededor de lo afectivo y pragmáticas}

Encontramos para esta subjetividad femenina una gran cercanía a los modelos tradicionales de hacer pareja, que están en proximidad con la postura psicoanalítica freudiana cuando junta en la mujer la corriente tierna y el placer sexual (Freud, 1976 [1912]) y, por otra parte, con la ideología del amor romántico (Giddens,1992). En los discursos emitidos durante las entrevistas por un grupo de mujeres era reiterativo el asunto del placer subordinado al campo afectivo, como modalidad de construcción de la pareja, y en algunos casos, sacrificando el placer. En cierta forma, en este discurso aparece una relación amorosa subordinada al hombre; asimismo, las relaciones sexuales se juegan casi en el plano de una obligación propia de la mujer para con su esposo (y también con el único novio o compañero). Opera la idealización del afecto en un modelo de amor romántico con sacrificios personales para la mujer, por amor al cónyuge o novio o, en el caso de una menor subordinación, por un sentido pragmático para ella.

Para esta subjetividad, el inicio de la actividad sexual se establece a partir de una relación afectiva seria y estable (noviazgo), de la que se espera su conversión a matrimonio, tal como lo narra Constanza: 
No, yo no tenía novio ni nada antes. No, yo no viví nada con otra persona (risas). Yo no pensaba en eso (....) mi primera relación sexual la tuve con mi esposo (Constanza, mujer negra, 32 años, heterosexual, unión libre, con dos hijos, secundaria completa, obrera industrial, residente en Villa Rica).

Feminidades de este tipo enfatizan la importancia del afecto en su vida de pareja sacrificando el placer en sus relaciones sexuales. Esto puede apreciarse en algunos casos donde se renuncia a la vivencia del orgasmo y se da poca importancia al placer, siempre y cuando se viva con quien se ama, tal el caso de Estela

No, yo creo que más que sentir placer es saber que uno quiere a esa persona, que es lo más importante, para mí es eso (Estela, mujer mestiza-blanca, 24 años, heterosexual, soltera con un hijo, secundaria completa, obrera industrial, residente en Villa Rica).

Asimismo, es visible en sus discursos una obligación, un sacrificio al otro en función del afecto. Esto no se da tanto por el uso de la fuerza del cónyuge sino que parte de los imaginarios que ellas tienen sobre las vivencias en pareja, donde es importante cumplir con el papel de una mujer complaciente aun en los casos donde no haya deseo por parte de ellas. Esto se aprecia en demandas como el sexo oral, sexo anal y una disponibilidad para tener relaciones sexuales cuando ellos lo desean. La satisfacción a toda costa de la pareja se convierte para ellas en un imperativo.

Yo digo que eso del sexo oral no se debe hacer, ¿cierto?, no debería hacerse, no sé porqué se hace. Eso de tener relaciones por atrás tampoco. [¿่Sexo oral de la mujer al hombre?] Tampoco, pero pues como usted sabe que eso es lo que está de moda, le toca a uno. Pero no, eso no debería de ser. Pero ¡qué se va a hacer!. Esas son cosas que se las inventa el hombre y pues hay que hacerlas (Ana, mujer negra, 32 años, heterosexual, unión libre, con dos hijos, secundaria completa, obrera industrial, residente en Villa Rica).

Sin embargo, en estas feminidades subordinadas aparece una reivindicación importante, a la manera de una resistencia frente a la dominación masculina, sobre la fidelidad afectiva y sexual del esposo, compañero o pareja, lo cual marca un cambio profundo con respecto a la mujer sumisa y pasiva. Tal como lo plantea Ana:

Él estaba estudiando en la universidad y yo todavía no. Entonces una amiga que yo tenía era amiga de él, y ella me dijo que dizque «iAy Ana!, fulano de tal, él está contigo sólo por jugar». Cuando ella me dijo así yo simplemente 
decidí no volverlo a ver y ya. Y lo hice a un lado (...) Hasta hoy no lo he vuelto a ver. Y después llegó otro que tuve también, o sea, éramos novios, y después yo me di cuenta de que tenía otra novia más seria, entonces yo también dije: ¡Ay no! Yo casi siempre soy como la que los hago a un lado. O sea, yo no esperaba que ellos me dijeran, "no terminemos". Si yo veía que no se podía, entonces no se podía y yo me quitaba (Ana).

Para ella, y para otras mujeres, la percepción discursiva de la fidelidad femenina que acepta la infidelidad masculina ya no es más aceptada. Se observaría una mudanza significativa respecto de la cultura femenina analizada por Simmel (1934) para su época, en la dirección que Bozon (2005) indica para el contexto francés, cuando sugiere que en las sociedades contemporáneas la nueva normatividad sexual implica un gran cambio en la concepción de la fidelidad por parte de las mujeres. Ana -y otras mujeres que como ella valoran más lo afectivo que el placer sexual- manifiestan una exigencia de fidelidad por parte de su pareja.

Por otro lado, en determinadas mujeres de sectores populares, el vínculo afectivo se juega como un arreglo racional, sacrificando el placer y el amor romántico en la elección de la pareja, y privilegiando fines que operan desde ideales pragmáticos, bajo expresiones tales como "hombre bueno", "no rumbero", "buen papá". Para estas feminidades de mujeres de clases populares, la estabilidad de la mujer y de la prole hacia el futuro es más importante que el afecto y el placer. $\mathrm{O}$ mejor dicho, el afecto se desenvuelve con la rutina de la convivencia, amparada en la estabilidad emocional y económica mediante una figura masculina protectora que garantice, hacia adelante, alguna movilidad social ascendente.

Se casa uno o no tiene nada, pero esas pendejadas de estar con esos noviazgos largos, ¡no! (...) Como yo le vi las características del hombre que yo buscaba: un hombre sano, no le gustaba la rumba y veía que servía como para ser buen papá, entonces lo escogí y al poquito tiempo me casé con él y no me ha pesado porque vivo muy bueno (...)

Cuando te casaste ¿estabas enamorada de él?

No, yo me casé más bien por conveniencia, pero no económica, sino más bien de estabilidad emocional al verlo a él lo bueno que era (Inés, mujer mestiza-blanca, 55 años, heterosexual, casada, con dos hijos, estudios técnicos, docente de colegios privados de sectores populares, residente en un barrio de clase media-baja de Cali).

Se puede observar aquí que, en un comienzo, la relación no está mediada por el deseo en sus esferas erótica y afectiva, sino por cierto sentido práctico; como la propia Inés reconoce, había renunciado al amor romántico: 
Tú mencionaste que cuando te casaste no estabas enamorada de tu esposo, entonces ¿̇cómo hiciste para casarte?

Para mí no fue difícil porque yo cerré las puertas al amor y me fijé en la conveniencia más que en otra cosa (Inés).

Los fragmentos seleccionados sobre la vida amorosa y sexual de estas feminidades denotan prácticas e ideales que pueden ser más frecuentes entre mujeres de clases populares urbanas y peri-urbanas de diferentes colores de piel, todas con prole y sólo una en la actualidad sin pareja, algunas con un pasado familiar de origen campesino, aunque completamente proletarizadas, como es el caso de las mujeres negras obreras del norte del Cauca. Otra característica es que a través de sus biografías se observa que mantienen fuertes y duraderos vínculos con el hogar materno, y en algunos casos también existe un ingrediente necesario, vinculado al control de la sexualidad a través la exacerbación de la castidad y el rechazo a cualquier experiencia no heteronormativa.

\section{Feminidades que afirman el placer atado a un ideal afectivo}

En esta segunda subjetividad femenina se aprecian rupturas con la ya descripta, especialmente por el lugar otorgado al placer, pues éste tendría mayor relevancia en torno de lo afectivo, en cercanía de los ideales del amor romántico. Se valora, por parte de las entrevistadas, una mayor autonomía en delimitar y exigir lo que les gusta y sancionar lo que rechazan. En cuanto a la fidelidad, se aprecian cambios en relación con la anterior tipología. Se trataría de una subjetividad a favor del placer sexual, enmarcado fuertemente en una relación de pareja heterosexual idealizada, predominante tanto entre mujeres jóvenes como de más edad. A diferencia de la precedente, la primera experiencia sexual no conlleva la conformación de pareja. Sin embargo, sigue operando la asociación entre placer y afecto, mediante la experiencia del enamoramiento. El erotismo, así, exigiría un tiempo de espera para poder vivirlo, aunque ya sobresale cierta autonomía en la búsqueda del Otro.

¿En qué momento con tu novio empezaron a tener relaciones?

A los 8 meses, él me respetó mucho (...) (risas). Mira que yo me le insinuaba mucho, yo no sé pero a veces las mujeres somos muy lanzadas. (Sandra, mujer negra, 19 años, heterosexual, soltera, sin hijos, estudios técnicos incompletos, residente en un barrio de clases populares de Cali). 
La mutua satisfacción sexual en la pareja es concebida como el derrotero que da sentido a la construcción y sostenimiento de la misma como proyecto emocional, como lo describe Yorlani:

¿Qué saca uno con tener sexo si no hay amor! Eso no es lo mismo (...) Para mí el sexo tiene que ir asociado al amor, encadenada una cosa con la otra, porque yo digo, si esa otra persona le atrae a uno, las cosas se dan mejor, pero usted se imagina, que un tipo que ni siquiera sabe usted quién es y se lo trepó encima... Sí, a mí me resultó tan difícil, después de cuatro años tener relaciones, con el papá de mis dos hijos menores. ¡Ay! Eso fue difícil para mí, porque yo decía éste no es al que ya estaba acostumbrada, entonces eso es difícil. Entonces yo digo, "hay mujeres de sangre caliente". Entonces eso es como muy normal en ellas, o sea les da igual si lo conocen o no lo conocen, les da igual. Están prestas para eso (Yorlani, mujer negra, 32 años, soltera, con tres hijos, heterosexual, secundaria completa, obrera industrial, residente en el casco urbano de Villa Rica).

Para estas mujeres, hay que vivirlo todo en pareja, más aun cuando ello garantiza la perdurabilidad de la relación. Por lo tanto la relación placer-afecto se juega en una dinámica más equilibrada, donde el placer es permitido pero siempre que vaya acompañado del afecto. Con todo, para estas mujeres no son bien valoradas las relaciones ocasionales o por fuera de la relación amorosa.

Para tí, ¿el sexo siempre debe estar asociado con el afecto o basta con obtener placer?

Pues a mí me gustaría que siempre fuera así [con el hombre que se ama]. Me gustaría mucho que siempre fuera así porque yo no sé (...) yo soy una persona muy cariñosita, y uno estar ahí y el otro estar pensando en otra cosa no me gusta. Hay unos [hombres] que hasta pensarán, "ésa tan boba, tan ridícula", porque ellos van es por [sexo]... van es a lo que van (...). En cambio uno entrega más (...) entonces a mí me gustaría que siempre fuera eso (Dorelby, mujer negra, 20 años, soltera, sin hijos, secundaria completa, obrera industrial, residente en Villa Rica).

A diferencia de la anterior, esta feminidad muestra una mayor amplitud a la hora de gozar las experiencias sexuales. Estas mujeres le reclaman a sus parejas que los encuentros sexuales sean placenteros, por lo que la experiencia del orgasmo es muy valorada. No obstante, dejan por fuera prácticas sexuales consideradas no normativas. 
¿Cómo ha sido -o es-para usted un orgasmo?

El orgasmo es algo impresionantemente delicioso, o sea, yo creo que una de las cosas más ricas que uno no puede describir en el mundo es eso, porque es algo increíblemente rico, bacano, bonito, chévere, espectacular, en fin, lo mejor.

¿Está de acuerdo con las relaciones anales o el sadomasoquismo?

Al que le gusta le sabe y allá el que lo haga, pero yo no (Tania, mujer negra, 25 años, heterosexual, casada, con un hijo, estudios universitarios incompletos, residente en un barrio de clases populares de Cali).

Se aprecia en estas mujeres una menor subordinación al hombre en las relaciones erótico-afectivas, con mayores procesos de reflexividad. La vivencia del placer es pactada en algunos puntos. Ellas se reconocen como un sujeto de deseo que participa en la relación y en donde el sacrificio al Otro no es necesario si representa una negación al de ellas.

¿Cuando tú accedias a tener relaciones sexuales con tu pareja era porque lo deseabas o porque él te lo pedía?

Porque yo quería, porque el hecho de uno tener una pareja no quiere decir que porque él quiso yo lo tengo que hacer. ¡No!, porque si yo no quería, no quería y punto. Porque como te digo no me gustó estar sometida en ningún sentido. Si yo tenía una pareja y quería tener relaciones, lo hacía para sentirme bien, no para satisfacerlo a él (risas). Ahora, tampoco soy de esa mujer que por cumplir, por un deber. ¡No! Primero yo, segundo yo y tercero yo. Pero en cambio, sí sobre todo el respeto entre ambos (Ana Milena, mujer negra, 40 años, heterosexual, separada, con tres hijos, secundaria incompleta, trabajadora por cuenta propia en oficios varios, residente en un barrio de clases populares de Buenaventura).

La fidelidad sigue siendo un elemento importante, aunque negociable. Se reconoce la infidelidad en las mujeres pero con énfasis en una cierta clase de mujeres, o justificada como un acto de venganza, en caso que la pareja sea por su parte infiel. De ahí que continúe apareciendo la relación amorosa con el Otro y no desde el derecho al placer.

Frente a la infidelidad de los hombres, ¿te parece que las mujeres también son asi?

Pues algunas mujeres pienso yo que de pronto sí. Algunas mujeres sí, para ellas es divertido, uno y otro, y manejan esa situación así. 
¿Por qué cree que se da eso?

De pronto la desconfianza que ya hay sobre los hombres, “jah!, este man de pronto me la hace». Entonces para que cuando me la haga (...) a mí no me dé tan duro. Entonces de pronto puede ser eso (Nidia, mujer negra, 24 años, heterosexual, soltera, con un hijo, secundaria completa, obrera industrial, residente en Villa Rica).

En suma, esta tipología reuniría mujeres cuya condición erótica, al margen de sus capitales educativos y económicos, tiende a la complacencia y satisfacción recíproca con su pareja. Hemos agrupado así testimonios de mujeres negras obreras de una región semi-urbana industrializada (Villa Rica) y de clases populares, de Cali y Buenaventura que, a diferencia del primer tipo de feminidad, han pasado por una experiencia de mayor reflexividad en términos de Giddens (1991).

\section{Feminidades que separan el placer del afecto}

Esta tipología guarda semejanzas con la anterior pero a la vez se distancia, pues ya no es un requisito que el placer se articule al afecto y a la estabilidad de la pareja. Este fenómeno social va de la mano de transformaciones en la forma de concebir la fidelidad, vinculadas con procesos de autonomía de la mujer, que se vinculan a mayores niveles de escolarización y a experiencias de participación política en movimientos feministas. Se está más dispuesta a vivir la sexualidad sin atarla a un vínculo amoroso y sin aceptar aquello que impida el erotismo, por lo que se aprecia una mayor autonomía en relación con el placer sexual. Así, el placer se abre paso más allá de las fronteras de lo normativo y permite la exploración de experiencias poco convencionales.

Sexualidad con mucha intensidad.

Digamos que sin tabúes...

Sin ninguno, de nada nada, y entonces como en esa vaina de que yo sentía que nada era anormal, entonces yo sentía que todo eso que leía yo lo asimilaba para mi vida personal, y decía: "entre un hombre y una mujer no tiene que haber nada de nada y como se le ocurre la fantasía todo dejar como que volara".

Entonces ¿tú explorabas libremente, sin ningún problema?

Sin ningún problema, sí, tanto que disfrutaba yo del sexo, no me importaba y con tal de estar, y después me daba contra la espalda... Pa'que vea que uno se la buscaba. Yo sabía que por ejemplo cuando te dije que yo quedé 
embarazada y no sabía de cuál de los dos, fue con ese amante que tuve entonces (Leticia, mujer mestiza-blanca, 53 años, heterosexual, soltera, con dos hijos, estudios universitarios completos, asalariada de nivel ejecutivo, residente en un barrio de clase media alta de Cali).

Se aprecia en esta subjetividad femenina la posibilidad de experimentar relaciones simultáneas, paralelas. No obstante, llama la atención que ese placer sea permitido si hay algún tipo de vinculo afectivo, sin que importen la estabilidad o el rótulo del mismo. Si bien habría una mayor ruptura que en la feminidad anterior en cuanto a la vivencia del placer, continúa relacionándoselo al afecto, aunque la durabilidad en el encuentro amoroso/erótico sea menor. De este modo, esta feminidad rechaza el placer por el placer. En ella se acepta la experimentación erótica siempre y cuando sea con un Otro por el que se tenga afecto.

Como yo pensé que ya el otro había terminado conmigo empecé a salir [risas] y ya me cuadre con éste, y a los dos meses cuando yo estaba con éste, resulta que el otro apareció, pero yo estaba con éste y me sentía bien. En esa época empecé a manejar las dos relaciones. Para mí era al que me llamara primero, el que sonara primero al teléfono, entonces con ése salía, y de allí para allá si yo me comprometía con el uno, entonces ahí mismo le decía a mi mamá: "mamá, si llama [el otro] tal diga tal cosa” (...) Yo misma organizaba como la mentira y entonces mi mamá me alcahueteaba (Olga, mujer mestiza-blanca, 55 años, heterosexual, soltera, estudios universitarios completos, asalariada de nivel ejecutivo, residente en un barrio de clase media-alta de Cali).

Priman las experiencias eróticas por fuera del noviazgo, pero se siguen articulando al afecto; es decir, se debe sentir amor hacia el objeto de deseo y generarse una estabilidad emocional con éste.

¿Pero cuál era la relación para tí más fuerte?

Claro, la de mi novio, porque el otro era casado y tenía su relación y pues yo no lo quería si no para un momento, para salir con él.

¿Pero decías que te enamorabas o te llegaste a enamorar de alguno de ellos?

$\mathrm{Si}$, yo me enamoré del hombre casado, me hacía falta, por eso los fines de semana cuando yo no lo veía a mi me hacía falta. Como trabajábamos juntos en una empresa yo no veía que fuera el lunes para verlo otra vez, entonces nosotros nos veíamos de lunes a viernes, mientras el fin de semana él iba con su mujer y sus hijos. 
¿Y tú ibas con tu novio?

Y yo con mi novio, yo estando con mi novio me hacía falta el otro (...) pero yo nunca tenía, por ejemplo, como que relaciones de aventura. ¡No! Como que me encontraba con alguien a bailar y acostarme. ¡No! Eso sí que no. Yo tenía mis relaciones simultáneas pero en mi relación de pareja era estable (Leticia).

La fidelidad pasa a construirse más en la lealtad del afecto, de las emociones, que del placer. Se observan así procesos reflexivos que estas mujeres producen cuando racionalizan las consecuencias de ser infieles, por lo que también surge el placer como ganancia y búsqueda de la subjetividad:

Con el otro era el goce del sexo. Porque con Jorge había mucho amor, y era la ternura, y era el respeto (...) era como cuando uno está enamorado. Que vos das todo y vos sentís que hay una confraternidad allí. Que hay una cosa así, un lazo. Con Diego también había mucho amor, pero era el disfrute del sexo por el sexo (Nayibeth, mujer negra, 35 años, bisexual, primero casada y luego en unión libre, sin hijos, estudiante de doctorado, residente en un barrio de clase media de Cali).

En determinados casos estas subjetividades han podido producirse gracias a experiencias de participación política de las mujeres:

Y también el hecho de empezar a estar en la izquierda y ya con el feminismo, sí me dio elementos para tener relaciones eh... con los compañeros, pero sí desde el criterio del yo querer y el yo ser y qué pasaba, de poder elegir. [...] Pero yo estaba también en mi cuento, construyendo realmente una manera del ser mujer de otra forma, reivindicando mi sexualidad y reivindicando mi sentir que era lo más importante, yo no quería reprimirme lo que estaba sintiendo ni viviendo y también, pues la revolución nicaragüense dio mucha posibilidad a las mujeres en ese sentido (Ana Valencia, mujer mestiza-blanca, 55 años, heterosexual, unión libre, con un hijo, profesional, clase media).

De las cuatro mujeres de clases medias acomodadas, con 35 años y más de edad ubicadas en este tipo de subjetividad, tres de ellas son blancas-mestizas heterosexuales y una es negra y bisexual. En todas ellas aparece una experiencia erótica y afectiva reflexiva relacionada a su nivel educativo y, en una de ellas, a su participación en movimientos de mujeres y de izquierda. 


\section{Feminidades que se juegan por la intensificación del placer}

Para esta feminidad, el acento está puesto en el placer y no en el afecto. Se trata de mujeres con una opción lesbiana o bisexual. Ellas introducen una gran ruptura con las otras feminidades por cuanto se evapora el vínculo con los ideales del amor romántico de matriz heterosexual. La relación placer-afecto pierde importancia y con ello la concepción de la fidelidad. Se trata de una subjetividad femenina en la que podemos observar relaciones esporádicas y contingentes, con encuentros casuales en los que se reivindica constantemente el placer, por fuera de una orientación heterosexual.

(...) ya cuando ella me hizo sexo oral se sentía bacano, entonces como que de vez en cuando, como pàquitármela..., pero ya yo empecé a ver mujeres más bonitas y todo eso, pero en ese trayecto ya yo me voy [de Cali].

Entonces, con ella tuviste como unos encuentros esporádicos. Sí.

\section{¿No hubo romances? \\ No, nunca, sólo era sexo. \\ ¿Pero lo disfrutabas?}

Sí, yo lo disfrutaba, ¡claro! (María Isabel, mujer negra, 38 años, lesbiana, soltera, con un hijo, educación secundaria completa y cursos técnicos, asalariada eventual en el sector de comercio o como obrera industrial, residente en un barrio de clases populares de Cali).

En estas subjetividades se puede optar por una relación abierta que comprende la viabilidad de un contrato psíquico muy distinto al de la conyugalidad tradicional, pues se trata de una configuración afectiva diferente al ideal del amor romántico. La pareja amorosa está en continuo movimiento, bajo un acuerdo implícito de contrato abierto. Esta modalidad de vivir el placer sin restricciones afectivas se acerca a lo que -según Giddens (1992)- constituiría los proyectos de pareja en la modernidad, que dependen crecientemente de la capacidad de reflexividad del yo:

\footnotetext{
¿Saliste con otras mujeres?

$\mathrm{Si}$, como unos tres años.

¿Con cuántas mujeres?

No sé [risas], muchas.
} 
¿No tenían el carácter de novias?

No.

¿Cómo le llamabas a esas relaciones?

Amigas.

¿Cuánto duraban?

Lo que yo pienso es que para que tu seas novia de alguien tiene que existir amor, y no existía amor.

Pero, ¿duraban algún tiempo?

Si, yo con Tatiana salí un resto.

¿Cuánto es un resto?

Como un año.

¿Pero no la llamabas novia?

No, no estaba enamorada de ella.

¿Pero tenían sexo?

Sí (Claudia, mujer negra, 28 años, lesbiana, soltera, sin hijos, estudios técnicos y universitarios, asalariada en el sector de comercio, residente en un barrio de clase media de Cali).

Me gusta estar con alguien, salir, disfrutar, participar y conocer. Y si yo no veo que yo conozca a alguien y que no sea mi pareja, y quiero estar con ella (...) yo no le veo nada de malo [sonríe]. O sea, ¿cómo te explico?. De que a mí me gusta alguien, pero yo no la vea como muy pareja, sino estar, salir, pasarla bien, y una amistad (Estéfany, mujer negra, 29 años, lesbiana, soltera, sin hijos, tecnóloga, obrera industrial y de servicios, residente en un barrio de clases populares de Cali).

A partir de elementos biográficos de las entrevistadas, las subjetividades en estas identidades enfrentan frecuentemente situaciones que requieren una reflexividad del ego, porque se trata de nuevas formas de pareja. En todos los casos, las mujeres privilegian la autonomía sexual como condición fundamental y es por ello que predominan relaciones contingentes y esporádicas.

Aunque, en tiempo record, con la última persona que estuve, nos vimos el mismo día, nos conocimos, y ese día estuvimos sexo.

El mismo día, ese es el tiempo record...

... ese es el tiempo record. Sí, podría decir, esa fue una experiencia, que me acosté con una persona que la conocía la primera vez (...) También. En la misma persona, a uno le gusta, y la ve, y con esa persona está. 
$[\ldots]$

Una vez hice algo loco, eso fue como un arrebato, estaba en internet, en Cali, estaba chateando como a la tres de la mañana, y me dice si salís ya para acá tenemos sexo, y yo salí.

¿Pero ya habias chateado con ella antes?

No, esa misma noche llevábamos como dos horas. Llegué y tuvimos relaciones, y nunca más volví a verla.

¿Te gustó la mujer?

Pues sí, no puedo decir que me enamoré, ¡no! Sólo lo normal (Estéfany).

En estas feminidades, la valoración del placer a través del orgasmo parece ser prioritaria:

Bueno, ¿y qué tan importante es para tí en una relación sexual un orgasmo?

Muy importante. Porque podría decir que hay una satisfacción plena en la relación. Se supone que ese es el fin. Y uno tener una relación y no llegar a un orgasmo, es como frustrante ¿no? (Estéfany).

En este cuarto tipo de subjetividad femenina, la fidelidad como norma no antecede al proceso reflexivo del contrato psíquico de la pareja; parece evidente que forma parte, con otros componentes, de una negociación del afecto y el placer, como lo manifiesta la entrevistada:

No, yo no creo en la fidelidad. Yo creo en la lealtad, que es muy diferente a la fidelidad. Es que la fidelidad es un término hasta machista. Es que la gente piensa que cuando está con uno... y ya te puso una placa pues allá atrás: pertenencia de... tal persona. Que no puedes voltear a mirar, no puedes hablar, no puedes salir, no puedes... nada. Porque todo tu mundo tiene que girar alrededor de esa persona. Dejas de ser tú por ser de tu pareja. Todo lo que a tí te gusta hacer, lo dejas de hacer porque tienes que estar con tu pareja. Y la fidelidad no, o sea, no es.

¿Y la lealtad entonces qué es?

La lealtad es algo más fuerte. La lealtad es aquello que uno, antes de cometer el acto empieza a valorar a la persona con la que estés (...) "Es que yo soy fiel a mi pareja”. Y cuando no la están mirando están mirando a la otra y todo. (...) Eso es ilusorio. La lealtad es muy diferente. La lealtad es algo que uno mide a la hora de dejar. O sea, si yo he cons- 
truido muchas cosas valiosas con alguien, dejar todo por una relación esporádica, o por un capricho, ya no estaría... aparte de eso que ese valor de lealtad se mide con uno mismo, ¿no? Como uno mismo se sienta. No como vaya a herir uno a la persona sino como uno mismo lo haga, y como se vaya a sentir uno. Es lo más importante. (...) Entonces haga usted en la calle lo que le dé la gana, pero tenga un respeto y un valor por su pareja (Estéfany).

Los testimonios anteriores pertenecen a mujeres negras lesbianas, de diferente generación, edad y clase social. Lo que marca la particularidad de esta subjetividad femenina es la orientación sexual. Sin embargo, esta transformación afirmativa del placer en la identidad lesbiana es independiente del color de piel. En cambio, lo que llama la atención en el caso de las mujeres negras lesbianas entrevistadas es su radicalidad en la ruptura con una heterosexualidad naturalizada por ser mujeres negras, de acuerdo con el modelo biologista raza/sexo, en la dirección propuesta por la feminista afroamericana Laura Harris (1996). Por esa condición de subordinación, las mujeres negras lesbianas cuestionan profundamente el imaginario de un esencialismo cultural que le ha sido asignado a la mujer negra como madre heterosexual que sirve al hombre y a su prole, según se desprende del estudio clásico de Gutiérrez de Pineda (1996) sobre el rol femenino que favorece el "machismo sexual" en las regiones colombianas con predominio de población negra (1996:299-308).

\section{Racialización de los cuerpos de mujeres negras}

Aunque la tipología de subjetividades femeninas señale una creciente autonomización del componente placer sexual entre las mujeres de diferentes clases sociales y colores de piel en la sociedad colombiana actual, este proceso requiere ser leído en el marco de las determinaciones sociales. Nuestra hipótesis es que el factor racial pesa sobremanera en la alquimia de las categorías sociales en el campo de la sexualidad.

Las mujeres negras son sujetos racializados. Si, como lo señalamos antes, en los contextos culturales de mayor poblamiento negro su papel femenino -como mujeres de clases subalternas en una sociedad en donde la jerarquía social tiene que ver con el color de piel- pasa por la hipermasculinidad del hombre negro, este factor afecta su condición de mujer, su sexualidad y salud reproductiva, en la medida en que son percibidas ambiguamente bajo una mirada moral respecto de comportamientos "peligrosos y desordenados", pero al mismo tiempo, exótica y cargada de capital sexual. 


\section{La censura médica y moral}

A partir de una ideología del esencialismo cultural, las mujeres negras son colocadas como desordenadas en su sexualidad y salud reproductiva. Llama la atención al respecto el testimonio de una mujer blanca, ilustrada, feminista, de clase media, con una trayectoria importante en movimientos de mujeres y con un pasado cercano a la izquierda, quien se expresa en los siguientes términos respecto de las mujeres negras en el manejo de su sexualidad y con ello de sus feminidades:

Yo trabajé en Guapi dos años y yo ya dije, aquí no hay nada que hacer, y yo como pálida (mujer blanca), menos. Como ellas viven esa sexualidad, que uno se imaginaría con el manejo del cuerpo y el baile y todo, es tenaz (...). Yo daba talleres de sexualidad en Guapi y (...) ellas felices con otras cosas y con la arrechera, así les den duro, así no les den un peso, así las maltraten, son felices tirando [teniendo sexo], entonces yo dije, el día que una negra se convenza que puede tener más autoestima, que se haga valer, que sea más digna, se los contará a ellas, pero de pronto ese no es el sentir de ellas. (...) Teniendo un mundo de niñitos, y porque ellas dicen que necesitan reproducirse independiente de que coman o no coman para que su raza no se acabe, entonces uno ahí en qué se mete... Pero lo que te quiero decir es que lo que yo veo de pronto como problema, para ellas no lo es (...) Porque eso es animal, es que la sexualidad (...) es animal (...).

\section{La mirada exótica racial}

Una segunda forma de racialización despierta la ambivalencia entre un cuerpo negro y una sexualidad exótica -y por lo mismo más erótica- que convierte a las mujeres negras en depositarias de un "conocimiento y práctica sexual” específicos o, en otras palabras, de un "capital sexual" muy valorado por los hombres y otras mujeres blancas-mestizas. Dicha ambigüedad se hace más palpable cuando las mujeres negras rechazan estas valoraciones expresando que ellas no quieren ser sólo objetos del deseo por una hipersexualidad imaginada por la/el otra/o, que responde a estructuras y estereotipos raciales de la sociedad. Aquí no se trata, como en la primera manifestación, de una condena por la sexualidad sin control, sino de la exageración de una supuesta exuberancia sexual que convierte a esos cuerpos sexuados en objetos deseables, tal como advierte Daniela:

Yo se que manejo muchos complejos pero hay algo que a mí me sucede y me molesta sobremanera (...) Yo siento como que a los hombres les gusto, pero de una forma como sexual. Como que los atraigo sexualmente. En- 
tonces yo siento que hay veces que me involucro con los manes [hombres] muy rápido, y después como que "no, yo ya no quiero estar con vos", y si no lo hago rápido como que tampoco, entonces yo en realidad no sé, porque siento es como que no despierto como gusto más allá del sexo. (...) Porque, yo pienso y yo siento que de antemano los hombres piensan que porque uno es negra, es como más ardiente. Entonces de antemano ellos están pensando eso. Y te digo, a mí se me insinúan muchos manes con unas cosas... eso me molesta porque son muy tontos. (Daniela, mujer negra, 28 años, heterosexual, soltera, sin hijos, estudiante universitaria, tesista de biología de universidad pública al momento de la entrevista, residente en un barrio de clase media de Cali).

Hay que señalar que el efecto de racialización opera en los distintos grupos sociales, tanto en las mujeres de clases medias como en las de clases populares, independientemente de la orientación sexual de los sujetos. Como observamos a continuación, ni la orientación sexual ni la clase social marcan una forma diferente en la racialización de los cuerpos femeninos.

(...) sí, igual, como yo no soy tan negra, pues dicen que les gusta mi color. (...) Escucho esos comentarios de que les gusta más la gente de color, y eso. Pero pues a mí eso no (...) que sí, que por negro, que no le pasa nada. Que no se enferman. Todas las bobadas(...) Que aguantan más [son más sexuales], todas esas cosas (María Isabel).

Pues a uno siempre le dicen que uno debe ser muy buena pa'la cama, ustedes la negras, con esos cuerpazos; que cuando lo hacemos, cosas así (Claudia).

A veces me siento hasta mal. Porque yo digo «ay, ¿será que me ven por sexo? [risas]. A veces me siento mal, y me cohíbo con eso.

¿Te consideras una persona muy sexual por eso?

A veces pienso (...) que de pronto me ven como muy sexual. Porque es que por mi raza, como yo por lo regular con las personas que he estado han sido más claritas que yo, blanquitas (...), la mayoría de las personas blancas, tienen una fantasía con las personas negras. Que somos personas ardientes. Entonces algunas lo buscan a uno es por eso. Entonces cuando yo estoy, me siento así, me bloqueo, y pienso, “¡será que me gusta por eso?». No me gusta mucho (...) (Estéfany).

María Isabel percibe que, aunque existan comentarios generalizados alrededor de una sexualidad sobrevalorada de las mujeres negras, para ella esto no significa un "plus" o algo que le favorezca al momento de conseguir parejas sexuales, y más bien descalifica los comentarios de ese tipo. Al igual que María Isabel, Estéfany opina que tales comentarios están sobredimensionados. 
En un relato más extenso que realiza Estéfany sobre este punto encontramos también una preocupación de ella como sujeto, porque no comparte que las mujeres mestizas con las que ha tenido y tiene relaciones sexuales la vean sólo como objeto de deseo. Esta ambigüedad de sentido en lo que dice y experimenta Estéfany, podría estar asociada a una interiorización de los estereotipos etnosexuales que operan sobre las mujeres de su mismo color de piel, pero que ella se resiste a aceptar, debido a que no quiere permanecer sólo en relaciones esporádicas y busca vínculos más fuertes en sus relaciones. Aparece así un conflicto que atraviesa lo racial (en cuanto estereotipo) en relación con su identidad de género. En ella la desazón puede radicar en que no quiere verse muy masculina, aunque paradójicamente la mayor parte de sus relaciones son esporádicas. El efecto del color de piel entonces se hace más visible al sólo optar por relaciones eventuales en las que el afecto y el conocimiento más prolongado de la otra persona queda relegado por la vivencia misma del mero placer corporal.

La racialización de la sexualidad y la sexualización de lo racial, presentes en las mujeres negras heterosexuales y homosexuales entrevistadas, de diferentes clases sociales y generaciones, forma parte de su condición de subalternidad en la sociedad colombiana, debido al factor racial. No obstante, para entenderla mejor se precisa tener en cuenta que los grupos étnico-raciales dominantes (blancos y mestizos) también la experimentan, pero en un sentido contrario, sin menciones a una sexualidad "normal" en contraposición a una "exótica" o "salvaje". Esto se hace visible cuando interrogamos al sujeto subalterno: para el sujeto estándar (blanco-mestizo) sólo aparece cuando se compara con el Otro. Las mujeres y hombres indígenas enfrentan una situación diferente a la gente negra, aunque su análisis excede los alcances del presente artículo.

\section{Conclusiones}

Los resultados del análisis de fragmentos de biografías sexuales de dieciocho mujeres negras y mestizas-blancas entrevistadas, de diferentes clases sociales, generación, grupos etarios, orientaciones sexuales, estado civil y presencia de prole, en las ciudades de Cali, Buenaventura y en la cabecera del municipio de Villa Rica, sugieren varias hipótesis, a la luz del debate entre la perspectiva foucaultiana, el feminismo radical en torno de obras como las de Rubin, Mathieu y Wittig; la teoría queer de performatividad de Butler, y el psicoanálisis lacaniano en las miradas del propio Lacan y seguidores, como Rudinesco, Allouch, Chairo y Soler.

Ese debate se centra en el papel creciente del placer en la conformación social de las subjetividades contemporáneas, en nuestro caso, femeninas. Igualmen- 
te, los aportes desde la sociología vistos en la dirección de Simmel (1934; 1984 [1890/1918]), Goffman (1976; 1977), Giddens (1991; 1992) y Kaufmann (2003) ubican las relaciones entre identidad, lazo social y los cambios que hoy en día se experimentan -como lo advierten Bozon (2005) y Bajos \& Bozon (2008)- y ello permite una lectura micro y macro social de las feminidades. Esto va de la mano con lo planteado por Foucault en cuanto la acentuación del placer frente al deseo.

Hemos introducido metodológicamente, por otra parte, una modalidad del determinismo social a través del enfoque de la interseccionalidad, por cuanto se ha observado que las categorías puestas en juego -en el marco de una matriz de dominación (Collins, 1990) - tienen que ver, para cada entrevistada, con los hallazgos empíricos sobre sus subjetividades y sobre cómo opera en las mujeres negras el fenómeno de la intersección raza y sexualidad (Wade, 2009; Nagel, 2003 y Green, 2008).

Es cierto que todas las entrevistadas, aunque con variaciones muy importantes, tienden a reconocer las vivencias del placer como parte de sus vidas sexuales. Esto de por sí ya es un importante fenómeno sociológico contemporáneo. Sin embargo, en esas variaciones aparecen diferentes determinaciones sociales que hemos podido observar a partir de la tipología construida alrededor de cuatro subjetividades femeninas. Así, pesan más para los tres primeros tipos -con matices relevantes- las condiciones de clase por vía del nivel educativo, ocupación y tipo de barrio; mientras que para el cuarto tipo es más importante la orientación sexual, ya que, en la línea abierta por Foucault y que retoman las feministas radicales y la teoría queer, estas feminidades transgreden el principio binario de la sexualidad (Harris, 1996). Si para este tipo de feminidad los componentes de clase, generación y edad no tienen mayor efecto, en cambio, es predominante la soltería y la no presencia de prole con una excepción, lo cual se relaciona con la orientación no heteronormativa. El mayor peso de la prole se da para los dos primeros tipos; y el estado civil, sea de unión libre o casada, pesan más en el primer tipo; la condición de soltería es dominante en el cuarto tipo. No se observan efectos interesantes de generación y edad como podría esperarse. Sin embargo, consideramos entre los hallazgos que el efecto más fuerte observado sobre las determinaciones sociales tiene que ver con el juego de racialización de la sexualidad y sexualización de lo racial, ya se trate de heterosexuales u homosexuales.

Las sexualidades de las mujeres no heterosexuales, en la dirección performativa de Butler, problematizan el modelo de la hegemonía simbólica-falocéntrica. Para ellas, los espacios corporales de placer son completamente resignificados, valorando otros componente morfológicos en el campo real e imaginario: los senos, la boca, los espacios intersticiales, como lo ha mostrado Moncayo en su estudio sobre el fenómeno swinger (2011:85). 
Vemos en las tres ultimas subjetividades femeninas una tendencia a la negociación de lo íntimo que forma parte de las dinámicas sociales contemporáneas, que han permitido nuevas esferas de goce sexual de la mujer, gracias a lo cual se ha abierto una cierta "democratización" de lo íntimo. Esto ha posibilitado la reubicación de la sexualidad en la pareja, la que tiende a ser más equitativa y demandante, constriñendo cada vez más los postulados del amor romántico, para dar paso paulatinamente a una manera de amar más confluente en términos de Giddens (1992); aunque el cuarto tipo ofrece un vínculo más cercano a la pura relación sin compromisos, según este autor.

En donde menos se observa la reivindicación del placer es en las mujeres heterosexuales de sectores populares y obreros, con menores niveles educativos, tanto en mujeres negras como mestizas-blancas. Su afirmación, en tanto, es más radical en las mujeres negras lesbianas, quienes viven sin tapujos la separación de placer y afecto. Otro hallazgo igualmente importante es que en una sociedad como la colombiana, de capitalismo periférico, también se viven procesos reflexivos y de resistencia alrededor de la demanda de placer entre mujeres de clases subalternas. Desde el psicoanálisis esto puede relacionarse con la idea de una sociedad narcisista que atraviesa todas las clases sociales, sin que pueda ser caracterizada por ello como patológica. (Roudinesco, 2009).

No obstante la sobredimensión del placer, a partir de los testimonios de las entrevistadas advertimos que el lazo social a través del vinculo afectivo (amoroso) mantiene un valor importante en los procesos de individuación contemporáneos (Kaufmann, 2003; Bajos \& Bozon, 2008) en las distintas clases sociales, colores de piel, generación, grupo etario, estado civil, tamaño de la prole y orientación sexual. El afecto continúa siendo significativo para todas las feminidades abordadas en el presente estudio; se juega en tensión con el placer a lo largo de los cuatro tipo de feminidades construidas, que puede ir desde su renuncia en el primer tipo hasta su exaltación, en el cuarto tipo. En este sentido, una sexualidad libre como proyecto emancipatorio que niegue el campo afectivo es una ilusión que, inevitablemente, acarrea otras formas de sufrimiento o malestar, ante la imposibilidad de combinar placer y afecto, por lo que el debate entre un feminismo radical no heterosexual y una perspectiva lacaniana continúa.

El presente artículo se ubica en una lectura de la sexualidad contemporánea: la de la vivencia del placer como parte constitutiva de la subjetividad contemporánea. Una sexualidad que resquebraja las relaciones de sexo/género convencionales y abre la puerta a diversas expresiones del deseo sexual, retirándolas de una mirada patologizante, independiente del sexo biológico. Dicha sexualidad es analizada también, en una segunda instancia, como inserta en el orden social jerárquico que reproduce la dominación. 
En especial, nos interesa colocar la que se produce en la articulación raza-sexo (en Nagel (2003), etnicidad y sexualidad), que se sustenta en una naturalización biológica de ambos componentes a través de la producción de estereotipos sexuales que encarnan determinados grupos étnico-raciales. Esto se advierte en la racialización de los sujetos como cuerpos sexuados que, en nuestro estudio, es experimentado por las mujeres negras. 


\section{Referencias bibliográficas}

ALLOUCH, Jean. 2001. El sexo del amo, el erotismo desde Lacan. Córdoba, Arg.: Ediciones Literales.

BAJOS, Natalie \& BOZON, Michel. 2008. Enquête sur la sexualité en France. Pratiques, genre et santé. Paris: La Découverte.

BILGE, Sirma 2009. "Théorisations féministes de l'intersectionnalité». Diogène. Revue internationale des sciences humaines $\mathrm{n}^{\circ} 225$, janvier-mars 2009. p.70-88.

BOURDIEU, Pierre. 1979. La distinction. Paris: Minuit.

BOZON, Michel 2005. «La nouvelle normativité des conduites sexuelles, ou comment mettre en cohérence les expériences intimes?» In: MARQUET, J. (dir.) Normes et conduites sexuelles contemporaines. p.15-33. Louvain-La Neuve: Academia-Bruylant.

BUTLER, Judith. 1993. Bodies That Matter: On the Discursive Limits of "Sex". New York: Routledge.

BUTLER, Judith. 2004. Undoing gender. New York: Routledge.

CHAIRO, Luciana. 2010. "El afecto. 'Un enigma perturbador'” [on line]. Available at: http://www.elpsicoanalitico.com.ar/num8/index.php\#arte. [Accessed on 01.04.12].

COLLINS, Patricia H. 1990. "Black Feminist Thought in the Matrix of Domination". In:_-_-_- Black Feminist Thought: Knowledge, Consciousness, and the Politics of Empowerment. p.221-238. Boston: UnwinHyman.

EVANS, Dylan. 1997. Diccionario introductorio de psicoanálisis lacaniano. 1ra ed. Buenos Aires: Paidós.

FOUCAULT, Michel. 1977. Historia de la Sexualidad I. La voluntad de saber. México: Siglo XXI.

FOUCAULT, Michel. 1979. “Non au sexe roi”. In: Dits et écrits, 1954-1988, t. IV: 19801988. Paris: Gallimard.

FOUCAULT, Michel. 1983. “À propos de la généalogie de l'éthique: une aperçue du travail en cours». In: Dits et écrits, 1954-1988, t. IV: 1980-1988. Paris: Gallimard.

FOUCAULT, Michel. 1984. «Interview de Michel Foucault». In: Dits et écrits, 19541988, t. IV: 1980-1988. Paris: Gallimard.

FREUD, Sigmund. 1976 [1912]. Sobre la más generalizada degradación de la vida amorosa. Obras Completas. Vol. XI. Buenos Aires: Amorrortu.

GARCÍA, María. 2009. "El señor Foucault y eso que se dio en llamar sexualidad". Tramas. Subjetividad y procesos sociales. $\mathrm{n}^{\circ}$ 32. Los territorios del cuerpo. México D.F. p.31-62.

GESTIN, M. \& MATHIEU. 2010. "Claude Lévi-Strauss et (toujours) L' échange des femmes: analyses formelles, discours, réalités empiriques». In: CHABAUD-RYCHTER, D., DESCOURTERES, V., DEUREUX, A. \& VARIKAS, E. Sous les sciences sociales, le genre. $1^{\mathrm{a}}$ ed. Paris: La Découverte. 
GIDDENS, Anthony. 1991. Modernity and Self-Identity. Cambridge: Polity Press.

GIDDENS, Anthony. 1992. The Transformation of Intimacy. Stanford: Stanford University Press.

GOFFMAN, Erving. 1976. "Gender Display". Studies in the Anthropology of Visual Communication 3, p.69-77.

GOFFMAN, Erving. 1977. "The Arrangement Between the Sexes". Theory and Society 4, p.301-331.

GUTIERREZ DE PINEDA, Virginia. 1996. Familia y cultura en Colombia. 4 ed. Medellín: Editorial Universidad de Antioquia.

GREEN, Adam I. 2008. "The social organization of desire : the sexual fields approach". Sociological Theory 26: 25-50. Available at: http://www.jstor.org/stable/20453094 .[Accessed on: 16/07/2012]. doi:10.1111/j.1467-9558.2008.00317.x

HARRIS, Laura Alexandra. 1996. "Queer Black Feminism: The Pleasure Principle”. Feminist Review $\mathrm{n}^{\mathrm{O}}$ 54. Contesting Feminine Orthodoxies (Autumn), p.3-30. Available at: http://www.jstor.org/stable/1395608. Accessed on 16/07/2012.

KAUFMANN, Jean. 2003. Sociologie du couple. Paris: Presses Universitaires de France (PUF).

LACAN, Jaques. 1973. Psicoanálisis, radiofonía y televisión. 1ed. 1977. Barcelona: Anagrama.

LACAN, Jaques. 1988. Seminario VII. La Ética del Psicoanálisis. Buenos Aires: Paidós.

MARTIN ALCOFF, Linda. 2006. Visible identities. Race, gender, and the self. New York: Oxford University Press.

MARTIN, J. \& GEORGE, M. 2006. "Theories of Sexual Stratification: Toward an Analytics of the Sexual Field and a Theory of Sexual Capital" [on line]. Available at: www.asanet.org [Accessed on 10.11.2011].

MATHIEU, Nicole-Claude. 2005 “¿Identidad sexual/sexuada/de sexo? Tres modos de conceptualización de la relación entre sexo y género ”. In: CURIEL, O. \& FALQUET, J. El Patriarcado al desnudo. Tres feministas materialistas. Buenos Aires: Brecha lésbica.

MONCAYO, Eduardo, J. 2011. El swinger: entre el placer y el afecto, rupturas y continuidades en la pareja contemporánea. Cali: Editorial Bonaventuriana.

NAGEL, Joane. 2003. Race, Ethnicity, and Sexuality. Intimate Intersections, Forbidden Frontiers. New York: Oxford University Press.

ROUDINESCO, Elizabeth. 2009. Nuestro lado oscuro. Una historia de los perversos. Barcelona: Anagrama.

RUBIN, Gayle. 1996. "El tráfico de mujeres: Notas sobre la "economía política” del sexo". In: LAMAS, M. El género: la construcción cultural de la diferencia sexual. México: PUEG.

SIMMEL, Georg. 1934. Cultura Femenina y otros ensayos. $1^{\mathrm{a}}$ ed. Madrid. Revista de Occidente. 
SIMMEL, Georg. 1984 [1890/1918]. On Women, Sexuality and Love. New Haven: Yale University Press.

SOLER, Colette. 2011. Les affects lacaniens. Paris: Presses Universitaires de France (PUF).

URREA, F., VIÁFARA, C. \& VIVEROS, M. 2011. “Colombia: una pirámide social pigmentocrática”. Informe Final Proyecto PERLA. Versión preliminar en español p.81.

WADE, Peter. 2009. Race and sex in Latin America. $1^{\text {a }}$ ed. London: Pluto Press.

WEST, C. \& ZIMMERMAN, D. 1999. «Haciendo género». In: NAVARRO, M. \& STIMPDON, C. Sexualidad, género y roles sexuales. p.109-143. Buenos Aires: FCE.

WITTIG, Monique. 2010. El pensamiento heterosexual. Madrid: Egales. 